\title{
VERSITA
}

$10.2478 /$ cris-2013-0008

\section{AGEISM AND AGE DISCRIMINATION IN THE WORKPLACE}

BARRY VELDON

The overall quality of life of older people is largely impacted by their participation and engagement in society and remaining active within the work place. This article researches this area in greater depth in terms of the impact of the ever increasing ageing population has on employment opportunities for this group of people and the political and social changes that are being implemented to support this issue. Using a combination of quantitative and qualitative approaches looks to investigate key dimensions of age discrimination that can lead to the elder generation being unable to fulfill this requirement. It views the perspective from both employee and employer regarding changes in legislation and how 3 individual organisations have implemented policies to align with these changes and then further explore the employees' knowledge of this legislation and their rights within the work place. 
There has been a growing awareness within governments, organisations, and generally within the public sector and in countries across the world that the shift in the increased age of the population is now being recognised as having widespread implications for everyone in society. Age equality has come of age. Less favourable treatment on grounds of race, gender, and disability has long been unlawful, but discrimination against older people in jobs and services has been justified by stereotypical assumptions about capacities or preferences associated with age. In some respects, discrimination against older people is even protected by law. That complacency is now being challenged for three reasons: the implications of Europe's ageing population for the labour market and for retirement income; the growing evidence, and public awareness of, age discrimination; and the changing expectations of older people themselves. Tackling age discrimination is now firmly on European and national political agendas (Spencer and Fredman, 2003).

\section{AN AGEING SOCIETY}

The understanding and concept of ageing can be categorised by the effects it has on an older person's life within their workplace, their home, and society in general. Aspects of ageing can be considered by the physical age of the person, psychological, and social age of a person. Theories around the adaptation, energy level, and productivity lead to barriers being created and lead to fewer promotion opportunities or job offers and/ or stereotypes associated to them mean ageing workers represent a highly heterogeneous category. There has been large criticism as previous research has not taken into account the diversity of ageing.

Organisational thinking differs in their definition and age threshold; they vary from business to business and in some cases country to country. In some sectors, such as advertising and IT, an employee as between 40 and 45 can be the victim of age discrimination because they are deemed not suitable for the job due to the fast track technology involved in this type of work. It seems that everyone, at least at some stage in their lifecycle, will be connected with some form of age discrimination. There are widespread myths associated with older workers which organisations feel will make them less productive. A common belief is that age often is associated with poor health or loss of cognitive capacity. In fact, in many cases older people are compensated for any deterioration in physical or mental capacities by drawing upon their workplace experiences, which should be taken into consideration in the hiring process.

\section{DEFINITION OF AGEISM AND AGE DISCRIMINATION}

The terminology "ageism" has widely been used to describe the systematic apparent stereotyping of older people. These were made up of three connected elements of discrimination:

- prejudicial attitudes towards older persons, old age and the ageing process;

- discriminatory practices against older people; and

- institutional practices and policies that perpetuate stereotypes about older people.

Macnicol (2006) has recently added that ageism is basically the application of assumed age-based group characteristics to an individual, regardless of the individual's actual characteristics. The substantive problem, he notes, is that ageism is embedded in patterns of thinking, which manifests itself in subtle as well as overt ways that lead general acceptance of age-related decline as inevitable (Macnicol, 2006, p. 6). In the 1990s, the issue of age discrimination gained momentum with greater awareness of this phenomena and the impact the size and age dynamic of the labour force would have on society and businesses. This was commonly called the "demographic time bomb". Organisations had to significantly address and change their attitudes towards older workers. 
A survey in 1992 across Europe revealed that over three quarters of EU citizens believed that older workers were in some way the victims of discrimination and companies were not hiring them or providing existing employees with promotion and training opportunities. The European Commission, advised specialist groups such as the European Industrial Relations Observatory (EIRO), to undertake studies which review the prevalence of discrimination and provide solutions to address age discrimination in employment. Comparisons on company practices demonstrated that amongst others, Great Britain and France were two countries where employment decisions based on age in are common place.

\section{LEGISLATION IN BRITAIN AND THE CZECH REPUBLIC ON AGE DISCRIMINATION}

A significant transformation in recent years within the United Kingdom has seen changes to legislation. There are now comprehensive laws relating to employment and the prohibited acts of discrimination regarding, race, disability, sexual orientation, age, gender, and religion. Rights for older workers came were introduced in 2006 and laws were put in place against age discrimination in employment. Regulations regarding retirement age were also considered and an employee's request to continue working past the normal retirement age of 65 was implemented. The Czech Labour Code prohibits discrimination in labour relations whilst discrimination against job applicants during the recruitment process is prohibited in the Act on Employment. The Labour Code contains a general prohibition against discrimination only but a further act; the Anti-Discrimination Act which covers discrimination on the grounds of sex, age, disability, race, ethnic origin, religious affiliation, and faith or worldview in several fields including access to employment, business, education, healthcare, and social security. This act has been in place since 1 September 2010. The last member state of the European Union to adopt anti-discrimination legislation was the Czech Republic. The Chamber of Deputies passed the Anti-Discrimination Act, which put in place a process to avoid heavy penalties for not implementing the requirements mandated in the EU Race Equality Directive.

\section{RESEARCH DESIGN}

The researcher considered the main approaches to methodology and chose to use the method of triangulation. The reason for this is it allowed for the use of more than one method of research, allowing the researcher to develop his studies and enhance his knowledge in the chosen area. A hypothesis was not used because the research used the method of induction. This allowed the researcher to collect data, analyse it, and from the analysis, and a theory can be developed which can then be tested, if necessary, by further research.

The research questions were been broken down into several subsidiary questions which provide structure for the research. Firstly, what is the extent of ageism and age discrimination in the work place? Secondly, what is the awareness of the employee of their rights regarding age discrimination? Thirdly, what is the relationship between employee and employer and how organisations are adopting current legislation that has been passed to combat this issue in the workplace? The questionnaire was randomly distributed across 3 organisations, Honeywell, Dell, and DHL. A total number being completed 124. The content and response required to the questions were broken down into separate elements. The first 1 - 6 questions related to the overall profile of the organisation and gave an insight into the individual employee status. The second element questions 7 - 11 looked at an individual's knowledge of his/her rights and current legislation in the workplace. Finally, questions 12 - 14 were specific instances of personal experience regarding the prevalence of age discrimination. SPSS (Statistical Package for the Social Sciences) was also reviewed for usage, but deemed unnecessary due to the nature of the data. Excel files were complied to manage the data. 
Prior to distribution of the questionnaire research was completed as to the total number of employees in each company in order that the sampling group was prorated to each organisation size as not to disrupt the data analysis. Therefore, a 10 per cent survey of the organisational population was reviewed, i.e. Honeywell has 330 employees, and therefore 33 questionnaires were taken; likewise Dell has 200 employees, therefore 20 questionnaires were completed, and DHL 710 employees, so 71 questionnaires were completed with a total of 124 responses and data gathered to form the findings below. The majority of the respondents were male, out of 124 respondents 17 per cent were female and 83 per cent male. It is not clear why there were more males than females, but it is likely that the role of the DHL organisation that makes up the larger number of the categories is the logistics hub in Prague and predominantly has logistic/ warehouse staff whilst the other two organisations are clerical by nature although still showing a greater degree of male employees overall.

Within these 3 organisations there is a trend already evident that within the hi tech/fast moving environments of aerospace, logistics, and IT that these types of firms attract the younger individual with an overall 76 per cent under the age 40 and 92 per cent under the age of 50. The correlation graph clearly details that the greater the number of employees, the lower the age band becomes. This gives way to a much larger question, and further research is required into the skills gap or desire of the older generation to work in these environments and can they in fact fit in to these modern organisations, or are there other types of roles that are more suited to this generation and less likely to attract the younger worker.

The purpose of the first question was to clarify the extent of non-national or expat workforce within the 3 sampled organisations; if these individuals were a large percentage of the sample, they may not necessarily know or need to know due to the length or their contract with the local government legislation (Anti-Discrimination Act, No. 198/2009 Coll.) or rights of workers regarding age discrimination within the Czech Republic. As detailed, 121 out of the 124 - 97 per cent equate to local employees with no foreign employees within the sample group, which will assist in substantiating responses later in the findings.

As detailed in the introduction, questions 1-6 were regarding the profile and organisational structure of the company and individual status of respondents. This gave the researcher a holistic view of the sample group to understand and confirm that this in fact covered a range of the organisation enough to provide variation in response levels. The data table distribution reflects that all levels within the organisation were covered within the sample group displaying a gradual step up through the managerial chain. This may also be correlated to the age groups of the respondents as in many organisations senior leadership positions are held by experienced managers within the upper age groups. Referencing data in question 3 , it showed that there were 7 respondents between the ages of 50-59 and 2 respondents 60 and over.

The last in the first element of questions which content seeks to gain a profile of the organisation and the respondent's general details looks at the time this sample group have been employed within each of the organisations. The largest area of responses came from group B which covered more than 1 year but less than 5, with only 27 out of the 124 (21\%) total responses being longer than this period. Without more specific data on each individual circumstance, the researcher was unable to conclude why this phenomenon existed; however again with the type of companies included in this research and information from previous questions, it is likely to indicate a seemingly young workforce. It can also indicate the changing thoughts of modern employees as not to have the need to stay in one role or organisation for a long period without moving on or higher in another company. The days of a job for life are over, and there has been a growing trend of frequent movement within companies being beneficial in an individual's career path. 
The second section of questions 7 - 11 reviews a more in depth study of the individual respondent's knowledge of rights and legislation and the level of importance they place on these within their career. Although clearly response $B$ (well informed) was the larger percentage of responses, the greater number in this category comes from DHL, but in the other 2 organisations, Honeywell more so, there was a perception of not being informed. This again could actually be based on the company's own policy of keeping their employees informed of their rights, or just the general culture found in $\mathrm{DHL}$, or Honeywell being different and therefore creating a different result. The data indicated that the responses to this question were evenly split with only a slight bias towards response B (a need to know more). A conclusion that is more evident out of the graph and that is not so visible in the data is that respondents in both Dell and DHL were relatively even, however in Honeywell there was a clear distinction between $A$ and $B$ with $81 \%$ responding that they needed to know more. This does not seem to be directly related to the age of individuals within this company as opposed to the other two as when referencing data table results from question 3 all have a majority of employees between the ages 30-39 with neither being disproportionate to the other. There is a direct relationship between the results of question 7 and 8 and individual employees are not as informed about their rights as those of DHL and Dell. This could be a serious issue within Honeywell regarding employee engagement and the HR department's role in informing the staff of their rights. $72 \%$ of responses fell in the lower two available answers and indicates a definite knowledge requirement for employees regarding the Anti-Discrimination Act (Act No. 198/2009 Coll.).

For the last element of questions the researcher elected to provide deeper investigation into the correlation between the age of the respondent and the answers provided. Graphs have been created for questions 9-14 where the correlation coefficient which is the square root of $R$ calculated. The correlation coefficient $R$ tells you the relationship between the variables on the $Y$ axis and the $X$ axis. $A$ high value $R$ means good correlation between the two variables. A standard scale for interpreting the strength of the relationship between the two variables using the $\mathrm{R}$ squared correlation co-efficient is:

- $0-.04$

- $.05-.16$

$\bullet .17-.36$ very weak

weak moderate
- $.37-.64$ strong

- $.65-1.00$ very strong

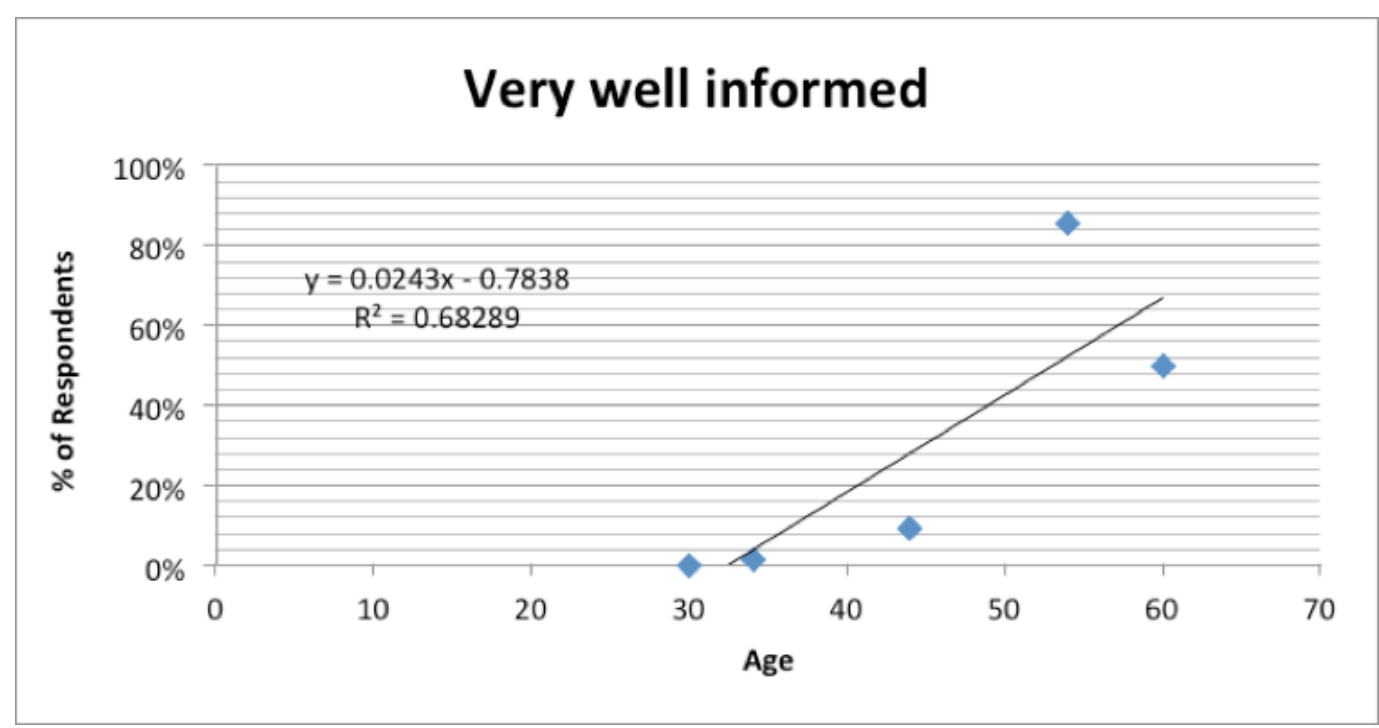




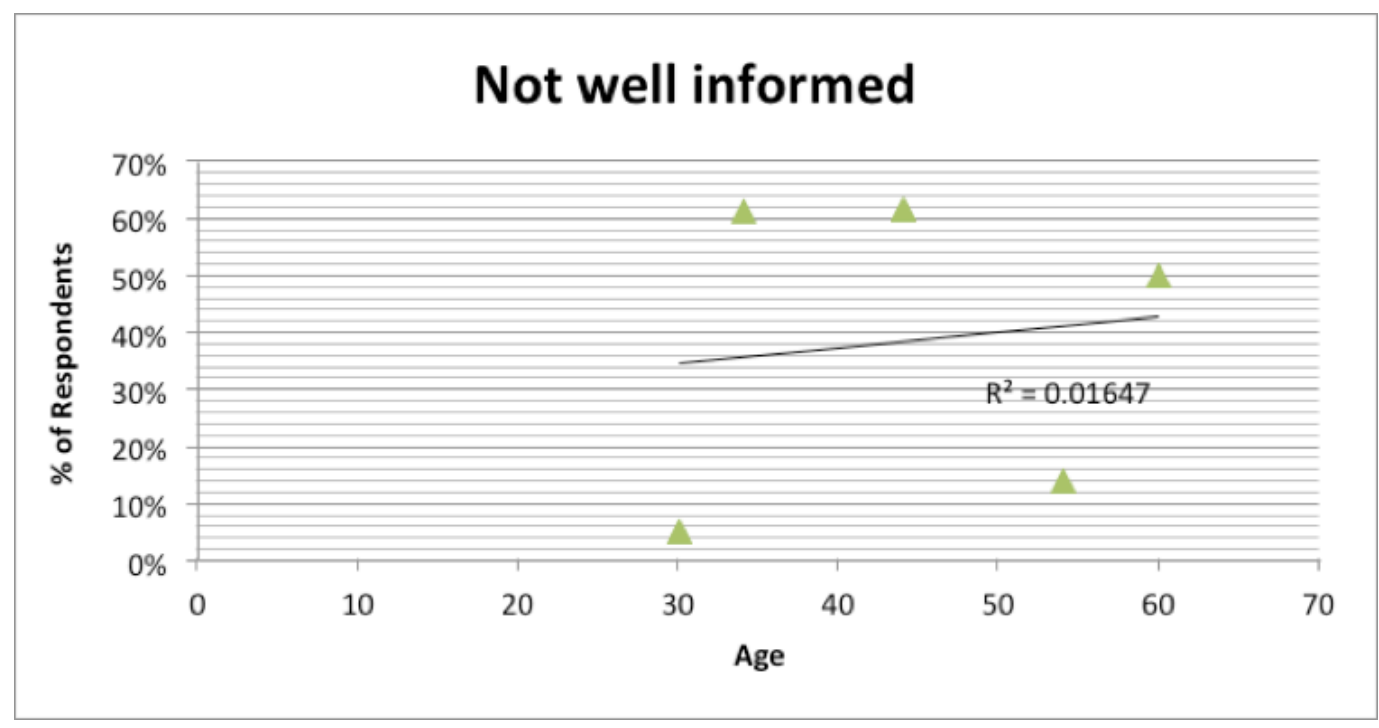

The correlation graphs detailed above indicate that there was a direct coefficient between the age of the respondent and the level of knowledge they held regarding legislation. The top graph clearly indicates an increase from not well informed to very well informed as the age of the respondent increased with a coefficient of 0.682 . As the analysis was being completed, there was a sub-group of the sample population across all age groups that responded to ' not informed at all', but this number did not detract from the conclusion made above.

It is interesting to see that although as indicated by results in the previous question, (how much did individuals know about the detail of the law regarding Anti-Discrimination Act (Act No. 198/2009 Coll.) where there was a clear lack of knowledge of the Anti-Discrimination Act (Act No. 198/2009 Coll.) that 94\% of the respondents indicated that they expressed the importance to know the details contained within this act, $50 \%$ of which indicated by responding to answer $A$ it was very important.

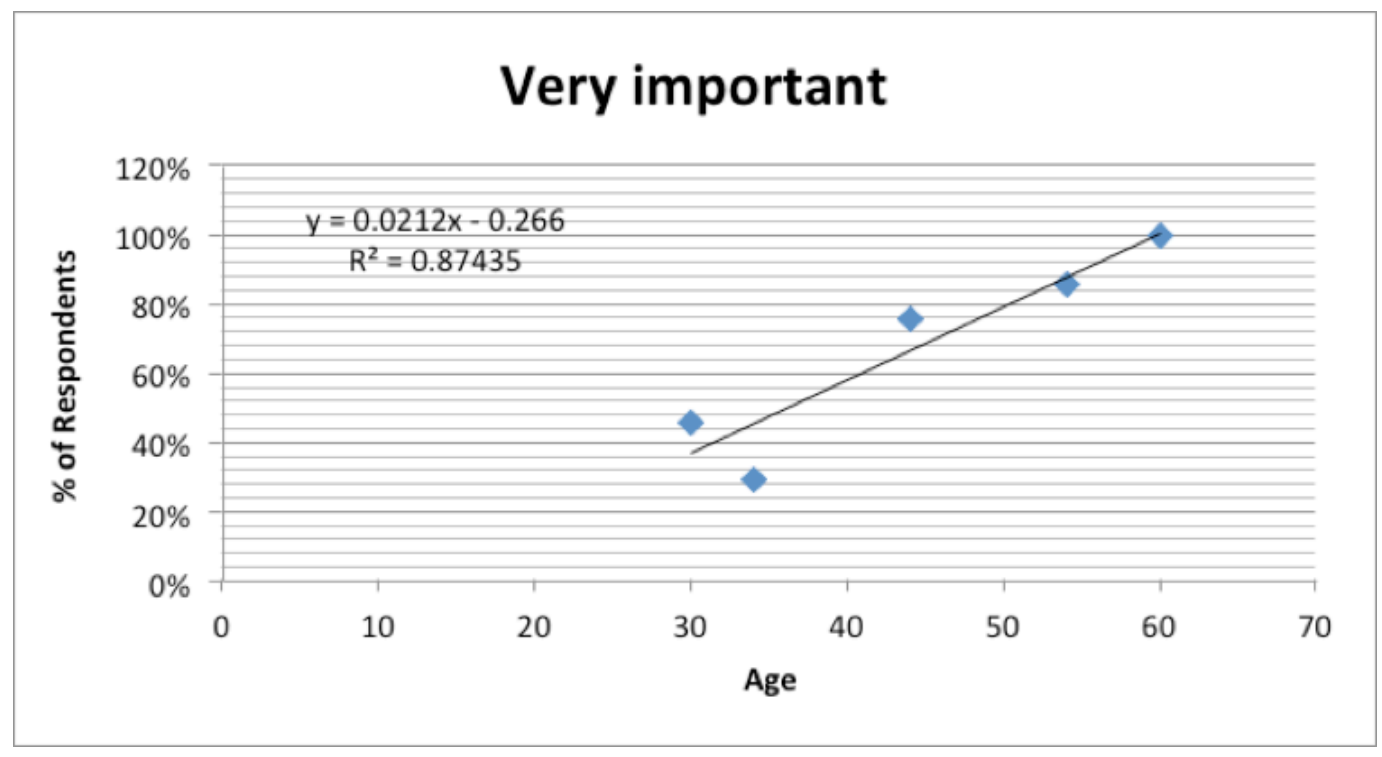


The correlation details an extremely strong relationship $(R=0.874)$ between the respondents age and the level of importance placed on importance of knowledge regarding legislation. The level of importance and understanding was significantly higher above the age of 40 . This further amplifies the response to the previous question that as age increases the awareness of legislation and the importance it holds are linked. The analysis of results to this question indicate a proportional response across the three organisations with $66 \%$ in favour of employers putting in place procedures on retirement for allowing continuance of work should both the employee and employer wish to do so.

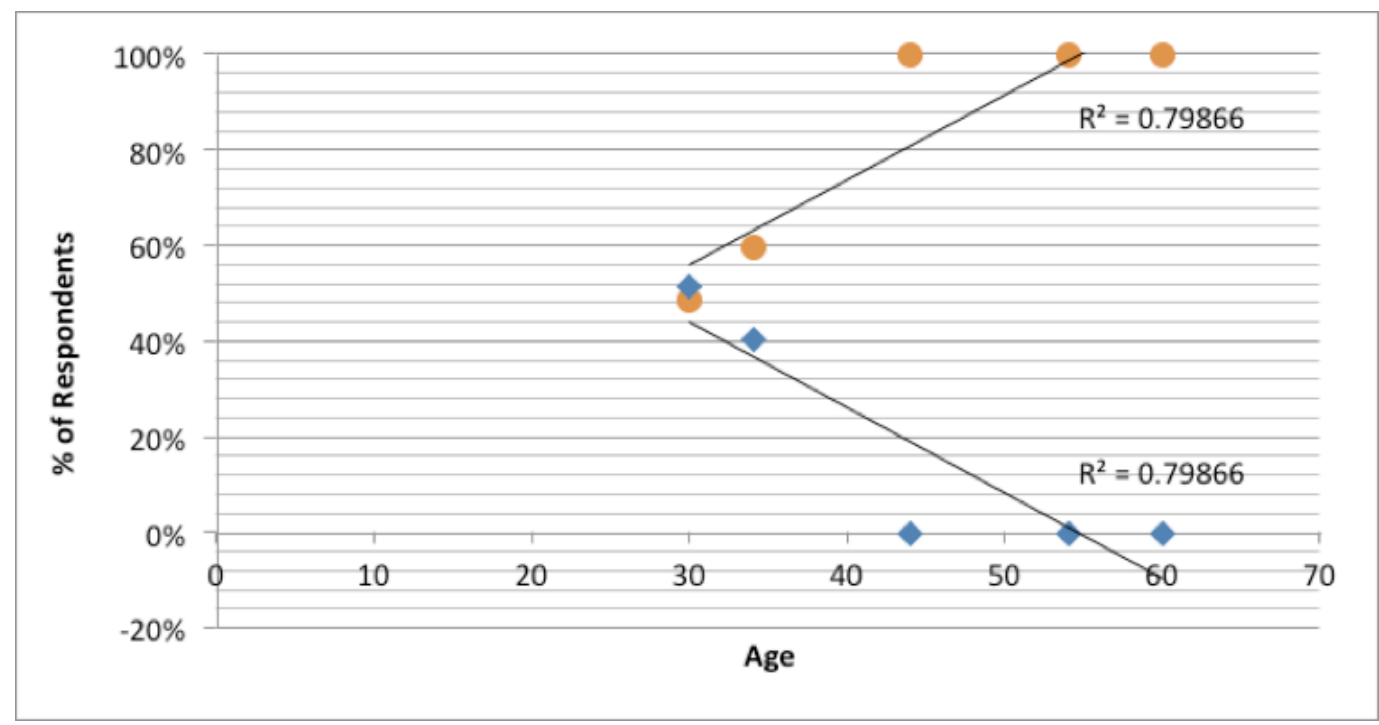

The strong correlation $\mathrm{R}=0.798$ clearly indicates a increase in a move to ' $y e$ ' $^{\prime}$ in the older age group that in $100 \%$ of the sample population greater than the age of 40 indicated 'yes'. Conversely, the co-variant ' no' reduces between ages 30-40 and there appears to be an even response at this age range. In reality these statistics hold true as with age an employee becomes more aware of the situation around them regarding stability of work, pension plans, and financial responsibilities, and is more inclined to be thinking about his/her long term working future and the retirement age. More specifically, the possibility of working passed the normal retirement age of 65 . This opens up a different study potential as to the need both financially and personally to work past this age due to the changes in our social structure and financial burdens placed on individuals such as extended mortgages, university fees for their grown up children, etc.

Given the relatively small size of the sample group there were 20 from the total of 124 a $16 \%$ level of respondents that indicated that they had directly or witnessed a form of age discrimination. If this percentage was expanded to the full number of employees within the 3 companies (1240), this would relate to 198 individuals who had in some way experience age discrimination. Further to determining the level of experience of age discrimination, the researcher wanted to explore what action was taken by the individuals and who they were involved with regarding advice on either their rights or the action to take at the time of the occurrence. Although individuals went to a multiple of different people for advice, the data graph shows the largest interaction being between the employee and his/her manager and the employee and the personnel/ HR department. There was minimal correlation between age and the choice of which individuals went to for advice and age discrimination issues. 
$55 \%$ of instances resulted in the individual changing company with a further 5\% (1 case) changing departments. It was reassuring to see that the remaining 35\% were resolved with the response D (other) not being specified without further analysis being made. Further analysis via correlation showed no direct relationship to response and age; however it was noted that as age increased, there was a tendency to move away from changing company in the older age groups.

Again this shows true to life as in older age an individual employee is less likely to want to make that shift to a new company/working environment and is more likely to adopt a resolution either via internal transfer as opposed to leaving a company as the risk of reemployment may be high.

\section{FINDINGS FROM INTERVIEWS}

There were three semi-structured interviews completed by the researcher to provide a deeper understanding of the thoughts and experiences of discrimination from both an employer and employee perspective. Two separate interviews were conducted with HR Generalist personnel from Honeywell. One, working within the Prague office of the Czech Republic, the other in the Yeovil, UK, office. The intent of the interviews being to compare the staffing policies within one organisation from two entities in different countries to see if individual country law had effected the interpretation or implementation of such policies or if for any other reason there were variables in the responses provided. The third interview was conducted with a Honeywell employee who fell within the older aged bracket who had responded to the initial questionnaire. Again, the intent being to gain a deeper understanding of his original responses and individual thoughts on his rights and knowledge of local legislation regarding discrimination within the workplace.

It was evident that Honeywell in general had implemented employment policies to align with local legislation and were proactive in their hiring methods to include individuals within the older age range without discrimination. In is interesting to note from responses from Honeywell employees to question 12 that 6 from the 33 responses had experienced a form of age discrimination; so although these policies exist, there was a feeling from employees that they had been unfairly treated in some manner and that more could be done to expand the knowledge of individuals regarding their rights and local legislation. The findings concluded that there was a severe lack of knowledge regarding age discrimination legislation on behalf of the employees. The findings revealed that $16 \%$ of the total number of 124 respondents had directly experienced or witnessed a form of age discrimination. Therefore, a continued application by the legal system, government, and employers is needed to provide information and support to employees to ensure this understanding and a decline in age discrimination in any form exists in order to further improve the quality of life for older aged generation who would wish to continue working without prejudice up to and after the age of 65.

The coincidence of instrumental, socio-economic, and business pressures for tackling age discrimination society's need for an educated, healthy older workforce, business needs in a tight labour market, and public concern for the rights and dignity of older people regardless of the contribution they are able to make has created a powerful political impetus for policy change. But the overlapping arguments used for reform can cloud the reasoning behind it: whether we are banning age discrimination because it is in the interests of society, or the interests of employers, or because it is fair for older people. The danger in relying on instrumental reasons alone is that, in a particular instance, the desirability of investing in promoting age equality is overridden by competing interests; or those interests might be satisfied simply by some leveling up of conditions for older people, not by the provision of equality per se. The moral case for addressing discrimination and promoting equality rests on protecting the right of the individual; not their right simply to equal treatment but to equality of opportunity - providing the greatest possible level of choice and autonomy, underpinned by equal respect for the dignity of the individual. 
As with any kind of discrimination, it is often difficult to show its existence and further to take action against it as there still remain loop holes in the law and organisational policies that would make it difficult for an employee to take action under these grounds. It is the belief of the researcher that despite many changes in legislation and a significant cultural change in organisational management towards the hiring of the older aged employees that there remains an element of age discrimination in our work place and that a further detailed study into this pheromone will be required utilising a larger sample group of the population across differing working environments.

\section{REFERENCES}

Macnicol, J. (2006) Age discrimination: An historical and contemporary analysis. Cambridge: Cambridge University Press. 